\section{Friedrich August Hermann Koch zum 175. - dem Mitbegründer der Kahla AG und Porzellanfabrik Hermsdorf}

Am 18. Mai 1843 wurde dem Kaufmann Christian Jacob Eckardt die Konzession zur Errichtung einer Porzellanfabrik in Kahla erteilt und dort am 27. August 1844 die Fertigung aufgenommen. „Der ist gut geworden“, so wurde der erste Brand vom 23. Oktober bewertet. Nach Absatzrückgängen Ende der 1840er Jahre kam es am 17. September 1856 zur Zwangsvollstreckung der Eckardt'schen Liegenschaften. Der neue Eigentümer, Gutsbesitzer Friedrich August Koch aus dem Magdeburgischen, bekam nach Erlangung des Schutzbürgerrechts der Stadt Kahla am 14. Februar 1859 die Konzession zum Weiterbetrieb der Porzellanfabrik. Sein Sohn, Friedrich August Hermann Koch, erwarb am 25. August 1872 den gesamten Firmenbesitz.

F.A. Hermann Koch, vor 175 Jahren, am 1. Juni 1842, in Hornburg geboren, hatte als Unteroffizier der 3. Reitenden Batterie des Magdeburger Feldartillerie-Regiments Nr. 4 am Deutsch-Französischen Krieg 1870/71 teilgenommen. Bereits tätig in der väterlichen Fabrik ging er nunmehr selbstbewusst und mit viel Elan an die Modernisierung und Erweiterung des Unternehmens. Gemeinsam mit seinem talentierten Werkmeister Johann Bünzli führte er das Unternehmen in den 1880er Jahren zur größten Fabrik für Geschirrporzellan im Thüringer Raum. Für diese Verdienste wurde er am 16. September 1885 durch Herzog Ernst I. von Sachsen-Altenburg zum Kommerzienrat ernannt (Bild 1).

Gemeinsam mit dem Bankhaus B.M. Strupp in Meiningen wurde das Unternehmen per 5. Januar 1888 in eine AG umgewandelt und damit Kapitalzufluss für weitere Investitionen gesichert. Bereits das Ergebnis des ersten Geschäftsjahres der Gesellschaft belegt, dass man bis zur Kapazitätsgrenze ausgelastet war. Deshalb wurde in Hermsdorf-Klosterlausnitz der Bau einer neuen Porzellanfabrik beschlossen, die am 6. Januar 1890 als "Porzellanfabrik Kahla, Filiale Hermsdorf-Klosterlausnitz" in Betrieb ging (Bild 2). Zusätzlich wurde eine Porzellanfabrik in Zwickau/Sa. als weitere Filiale erworben.

In der Generalversammlung der AG am 16. Dezember 1890 wurde Hermann Koch zum Generaldirektor ernannt, doch bereits nach einem Jahr, am 21. Dezember 1891, schied er aus dem Vorstand der AG aus und Johann Bünzli übernahm als Direktor die Oberleitung des Kahlaer Unternehmens. H. Koch verlegte seinen Wohnsitz nach Hermsdorf in eine neuerbaute Fabrikvilla, die fortan den Namen "Villa Koch" trug.

In Hermsdorf wurde in direkter Nachfolge für Hermann Koch 1892 durch Geheimrat Dr. Gustav Strupp 0skar Arke an die Spitze der Porzellanfabrik berufen. Von der Porzellanfabrik H. Schomburg \& Söhne in Berlin kommend, die bereits ab 1866 Niederspannungs-Isolatoren produzierte, traf 0 . Arke in Hermsdorf strategische Entscheidungen für ein ganzes beginnendes Jahrhundert, indem er den sukzessiven Übergang der Fabrik auf die Fertigung von technischer Keramik, insbesondere Hoch- und Niederspannungs-Isolatoren, initiierte. Mit der darauf folgenden Entwicklung der DELTA-Glocke 1897 als erstem auf wissenschaftlicher Basis konstruiertem Hochspannungs-Freileitungs-Isolator durch Prof. Robert M. Friese erlangte die Porzellanfabrik Hermsdorf zunehmend Weltgeltung.

Im August 1894 beging die Porzellanfabrik Kahla ihr 50jähriges Gründungsjubiläum. In seiner Festrede ließ H. Koch die überaus erfolgreiche Firmengeschichte eindrucksvoll Revue passieren. Danach verlegte er

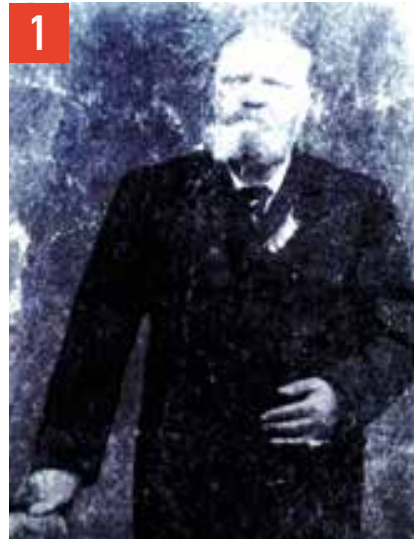

Bild $1 \cdot$ Kommerzienrat Friedrich August Hermann Koch

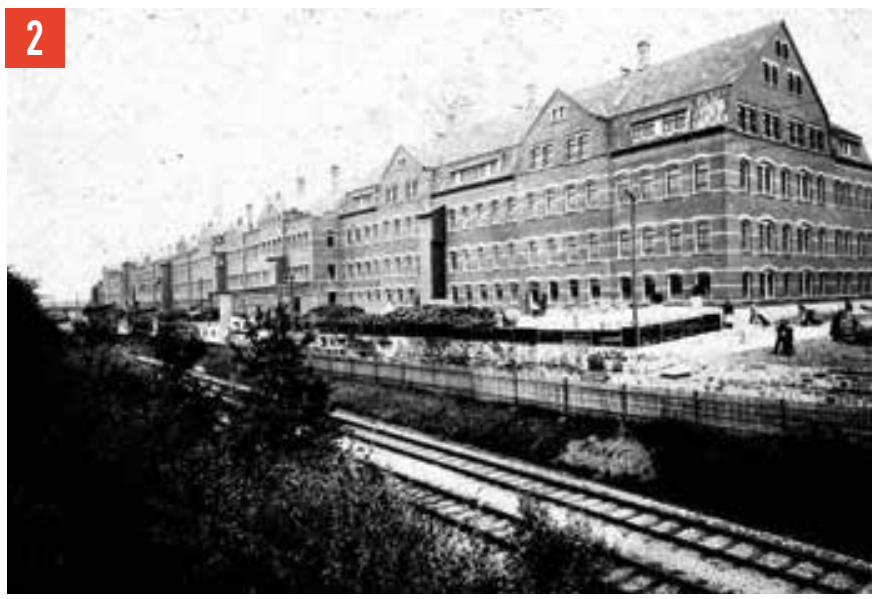

Bild 2 • Porzellanfabrik Hermsdorf-Klosterlausnitz

seinen Wohnsitz nach Dresden-Blasewitz und gründete zusammen mit seiner Frau Nanni Koch, geb. Campbell, die „Hermann-und-Nanni-KochStiftung" mit einem Startkapital von 3 Mio. RM. Am 8. Mai 1905 verstarb Hermann Koch in Blasewitz im Alter von 63 Jahren und fand auf dem dortigen Evangelisch-Lutherischen Johannesfriedhof seine letzte Ruhestätte. Auch nach mehr als 100 Jahren ist diese Stätte des Erbbegräbnisses der Familie Koch dank des Engagements der Friedhofsverwaltung in einem gepflegten und gut erhaltenen Zustand (Bild 3). Ebenso Kochs Lebenswerk, die Porzellanfabriken Kahla und Hermsdorf, haben den Stürmen des 20. Jahrhunderts widerstanden, jede auf ihre Art, und haben so erfolgreich in der Marktwirtschaft des 21. Jahrhunderts Fuß gefasst.

F. Kerbe

Quellen:

(Bildnachweis: F. Kerbe)

\section{Schrifttum:}

- Denner, R.: Die Geschichte der Porzellanindustrie in Kahla. J. Beck, Kahla (1930)

- 150 Jahre Porzellan. Kahla: Die Geschichte eines Unternehmens. KAHLA/Thüringen Porzellan GmbH (1994)

- Kerbe, F.: Die Entwicklung des Keramikstandortes Hermsdorf und seine Beziehungen zur Region Jena. Teil I: 1890-1945. Jenaer Jahrbuch zur Technik- und Industriegeschichte, Band 4. Glaux Verlag, Jena, (2002) 152-175

- Hauptstaatsarchiv Weimar, Bestand HESCH0, Akte Nr. 341 